\title{
Acute and second-meal effects of peanuts on glycaemic response and appetite in obese women with high type 2 diabetes risk: a randomised cross-over clinical trial
}

\author{
Caio E. G. Reis ${ }^{1 *}$, Daniela N. Ribeiro ${ }^{1}$, Neuza M. B. Costa ${ }^{2}$, Josefina Bressan ${ }^{1}$, Rita C. G. Alfenas ${ }^{1}$ \\ and Richard D. Mattes ${ }^{3}$ \\ ${ }^{1}$ Department of Nutrition and Health, Federal University of Viçosa, Avenida PH Rolfs, s/n, Viçosa, Minas Gerais 36570-000, \\ Brazil \\ ${ }^{2}$ CCA, Federal University of Espirito Santo, Minas Gerais, Brazil \\ ${ }^{3}$ Department of Foods and Nutrition, Purdue University, West Lafayette, IN, USA
}

(Submitted 13 April 2012 - Final revision received 10 August 2012 - Accepted 13 August 2012 - First published online 5 November 2012)

\section{Abstract}

Nut consumption is associated with a reduced risk of type 2 diabetes mellitus (T2DM). The aim of the present study was to assess the effects of adding peanuts (whole or peanut butter) on first ( $0-240 \mathrm{~min}$ )- and second (240-490 min)-meal glucose metabolism and selected gut satiety hormone responses, appetite ratings and food intake in obese women with high T2DM risk. A group of fifteen women participated in a randomised cross-over clinical trial in which $42.5 \mathrm{~g}$ of whole peanuts without skins (WP), peanut butter (PB) or no peanuts (control) were added to a $75 \mathrm{~g}$ available carbohydrate-matched breakfast meal. Postprandial concentrations ( $0-490$ min) of glucose, insulin, NEFA, glucagon-like peptide-1 (GLP-1), peptide YY (PYY), cholecystokinin (CCK), appetitive sensations and food intake were assessed after breakfast treatments and a standard lunch. Postprandial NEFA incremental AUC (IAUC) (0-240 min) and glucose IAUC (240-490 min) responses were lower for the PB breakfast compared with the control breakfast. Insulin concentrations were higher at 120 and 370 min after the PB consumption than after the control consumption. Desire-to-eat ratings were lower, while PYY, GLP-1 and CCK concentrations were higher after the PB intake compared with the control intake. WP led to similar but non-significant effects. The addition of PB to breakfast moderated postprandial glucose and NEFA concentrations, enhanced gut satiety hormone secretion and reduced the desire to eat. The greater bioaccessibility of the lipid component in $\mathrm{PB}$ is probably responsible for the observed incremental post-ingestive responses between the nut forms. Inclusion of $\mathrm{PB}$, and probably WP, to breakfast may help to moderate glucose concentrations and appetite in obese women.

Key words: Peanuts: Glucose: Appetite: Type 2 diabetes mellitus: Glucagon-like peptide 1: Glycaemic index

The incidence and prevalence of type 2 diabetes mellitus (T2DM) have increased markedly worldwide, and its complications are the leading causes of morbidity and premature mortality $^{(1)}$. The importance of diet in the prevention, treatment and control of T2DM has been recommended ${ }^{(2)}$. It has been reported that nut consumption may improve glycaemic control $^{(3)}$.

Peanut consumption may moderate appetite, food intake and glycaemic control, and has been negatively associated with type 2 diabetes risk $^{(4)}$. These beneficial effects may be due to their nutritional components. Besides being a low-glycaemic-index food, peanuts are energy dense, and a good source of fibre, protein, niacin, folate, $\mathrm{Mg}$, Se and $\mathrm{Mn}$.
They also contain bioactive compounds that exert antioxidant and anti-inflammatory effects ${ }^{(5)}$. However, the mechanisms responsible for their health benefits have not been completely elucidated ${ }^{(6)}$.

Processing whole nuts to butter form results in cell-wall rupture and greater fat and fat-soluble nutrient bioaccessibility ${ }^{(7)}$ The higher availability of fat in the intestinal lumen may decrease the rate of carbohydrate absorption (by delaying gastric emptying), favouring a reduced glycaemic response, and stimulate the secretion of intestinal hormones that may curb appetite and food intake as well as stimulate insulin release ${ }^{(8)}$ Therefore, the form in which peanuts are consumed (whole or butter) may lead to different metabolic responses ${ }^{(9)}$.

Abbreviations: CCK, cholecystokinin; GLP-1, glucagon-like peptide-1; IAAC, incremental area above the curve; IAUC, incremental AUC; PB, peanut butter; PYY, peptide YY; T2DM, type 2 diabetes mellitus; WP, whole peanuts without skins.

*Corresponding author: Caio E. G. Reis, fax +553138992541, email caioedureis@gmail.com 
The aim of the present study was to assess the effects of peanut consumption (whole peanuts or peanut butter) on first- and second-meal glucose metabolism (blood glucose, insulin and NEFA) and selected gut satiety hormone responses (glucagon-like peptide-1 (GLP-1), cholecystokinin (CCK) and peptide YY (PYY)), subjective appetite ratings (visual analogue scale) and food intake in obese women with high T2DM risk.

\section{Methods}

\section{Participants}

Study participants were recruited through public advertisements. Eligibility criteria included the following: age 18-50 years; BMI $30-35 \mathrm{~kg} / \mathrm{m}^{2}$; not taking medications known to affect glycaemia, fat metabolism or appetite; regular breakfast consumer ( $\geq 420 \mathrm{~kJ}$ ingested within $2 \mathrm{~h}$ of waking on $\geq 4 \mathrm{~d} /$ week); limited body weight fluctuation $(<5 \mathrm{~kg}$ in the past 3 months); willingness to eat all test foods; no self-reported allergy to the foods provided in the study; no self-reported sleep disorders. In addition to the aforementioned criteria, participants had to meet one of the following conditions: waist circumference $\geq 88 \mathrm{~cm}$; reported family history of T2DM in first-degree relatives; fasting capillary blood glucose $5.5-7.0 \mathrm{mmol} / 1$; and/or $2 \mathrm{~h}$ blood glucose $7.8-11.1 \mathrm{mmol} / 1$ (impaired glucose tolerance). Participants presenting with T2DM, dyslipidaemia or high blood pressure were excluded.

A total of 141 individuals completed the first screening visit, of which sixty-eight were eligible for and completed the second screening visit. Finally, fifteen participants met all screening criteria and completed the full study protocol.

The protocol was approved by the Human Research Ethics Committee of the Federal University of Viçosa, Brazil (no. 004/ 2009). The present trial was registered at ClinicalTrials.gov (registration no. NCT01413126). All volunteers were informed about the objectives of the study and provided written informed consent. Power calculations indicated that thirteen individuals were necessary to detect a change in blood glucose of $0.35 \mathrm{mmol} / 1(\alpha=0.05 \text {; power }=0.80, \mathrm{SD} 0 \cdot 3)^{(10)}$.

\section{Study design}

The present randomised cross-over clinical trial required participants to complete three experimental sessions where whole peanuts without skins (WP), peanut butter (PB) or no peanuts (control) were consumed with a breakfast meal separated by a washout period of at least $8 \mathrm{~d}$. Participants were instructed not to consume alcohol or conduct any non-habitual physical activity $24 \mathrm{~h}$ before the sessions, and to consume a low-carbohydrate meal the night before the test sessions. Postprandial concentrations of blood glucose, insulin, NEFA, GLP-1, CCK, PYY, appetite sensations and food intake were assessed before and after breakfast treatments and a standard lunch (Fig. 1).

For screening, participants arrived in the laboratory between 07.30 and 08.00 hours after a $12 \mathrm{~h}$ overnight fluid and feed deprivation for the $2 \mathrm{~h}$ oral glucose tolerance test, and for measurement of height, waist circumference, body weight, body composition, resting energy expenditure and blood pressure. Participants were also asked to answer questionnaires regarding stress, physical activity and eating and sleeping habits.

At each experimental session, body weight, capillary glucose level, the number of hours of sleep the night before and the time and composition of the last meal were assessed. Finger stick blood glucose was measured using a glucometer One Touch Ultra 2 (Johnson \& Johnson Company) to ensure that the participants were feed-deprived (glucose $<5.5 \mathrm{mmol} / \mathrm{l}$ ).

An indwelling catheter was placed in the participant's forearm and blood samples were drawn and appetite was rated at baseline (-10) and at 15, 45, 60, 90, 120, 180 and $240 \mathrm{~min}$ after test breakfast completion (first-meal responses). At $240 \mathrm{~min}$, participants consumed a standard lunch. Afternoon blood sampling and appetite scoring occurred at 265, 295, $310,340,370,430$ and $490 \mathrm{~min}$ after consumption of the test breakfast (second-meal responses), resulting in a total of $8 \mathrm{~h}$ of biochemical assessment. After leaving the laboratory, participants recorded all food consumed and filled out the appetite ratings $^{(11)}$ at 550, 610, 670 and $730 \mathrm{~min}$.

Participants were not allowed to eat or drink anything (except water) besides the foods that were provided during the study sessions. They were also not allowed to watch any television show or talk about anything related to food, or anything that could affect the assessed parameters. They were allowed to read, listen to music, watch TV, use the computer and walk inside the laboratory.

\section{Anthropometric and body composition measurements}

Body weight was assessed using an electronic platform scale (Model 2096 PP, Toledo Brazil), with a capacity for $150 \mathrm{~kg}$ and precision of $50 \mathrm{~g}$. Height was measured using a stadiometer (SECA model 206; Seca) fixed to the wall. BMI was computed based on weight $(\mathrm{kg})$ and height $\left(\mathrm{m}^{2}\right)\left(\mathrm{kg} / \mathrm{m}^{2}\right)$,

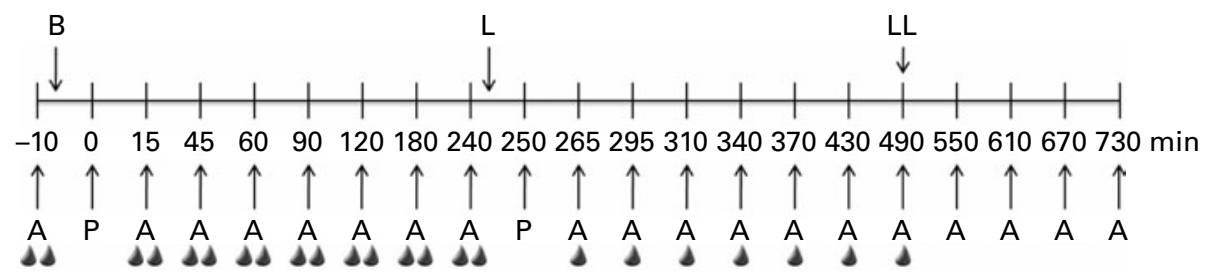

Fig. 1. Experimental study protocol. B, breakfast; L, lunch; LL, leave the laboratory; A, appetite; P, palatability; $\Delta$ s, glucose, insulin, NEFA, glucagon-like peptide-1 (GLP-1), cholecystokinin and peptide YY analyses; 1 , glucose, insulin, NEFA and GLP-1 analyses. 
and classified according to the parameters of the $\mathrm{WHO}^{(12)}$. Waist circumference was measured midway between the lowest rib and the iliac crest with a precision of $0.1 \mathrm{~cm}^{(13)}$, and classified according to the parameters of the Third Report of the National Cholesterol Education Program Expert Panel on Detection, Evaluation, and Treatment of High Blood Cholesterol in Adults ${ }^{(14)}$. Body fat percentage was measured by tetrapolar electrical bioimpedance (Biodynamics, Model 310, TBW) according to the protocol of Lukaski et $a{ }^{(15)}$. Participants were instructed not to use diuretics $7 \mathrm{~d}$ before the assessment, not to exercise during the preceding $12 \mathrm{~h}$, not to drink alcohol for the preceding $48 \mathrm{~h}$ and to avoid drinking any beverage $12 \mathrm{~h}$ before the test.

\section{Clinical assessments}

Blood pressure was assessed by auscultation with a recently calibrated aneroid sphygmomanometer. The measurement was performed during the initial evaluation by a trained professional, and classification of the values obtained was done according to the recommendations by Pickering et al. ${ }^{(16)}$.

The level of physical activity was estimated using the Johansson \& Westerterp ${ }^{(17)}$ questionnaire. Energy expenditure was estimated by multiplying the physical activity level obtained by the BMR calculated using the Mifflin et al. equation $^{(18)}$.

Participants were instructed to eat a hypoglycaemic meal for dinner on the night before. This meal was intended to contain only meat and vegetables. High-carbohydrate foods (i.e. breads, rice, pasta, potatoes, cassava, etc.) were not allowed. Once the participants arrived at the laboratory, their feed-deprived state was verified (One Touch Ultra 2, Johnson \& Johnson Company). An oral glucose tolerance test was performed on screening day and the participants were classified according to the American Diabetes Association ${ }^{(19)}$.

Homeostasis model assessment insulin resistance index was used to evaluate insulin resistance level. Pancreatic $\beta$-cell function was assessed by homeostasis model assessment pancreatic $\beta$-cell function according to the Matthews et al. equation $^{(20)}$. According to Geloneze et al. ${ }^{(21)}$, the cut-off point for insulin resistance diagnosis in Brazilian obese women aged approximately 40 years is $2 \cdot 71$.

\section{Test meal}

In accordance with the Food and Drug Administration ${ }^{(22)}$ -qualified health claim regarding daily nut intake, $42.5 \mathrm{~g}$ of WP or PB were added to a breakfast meal in each test session. On each testing occasion, each participant consumed a test breakfast within $10 \mathrm{~min}$ that consisted of orange juice (250 ml) (Tropical Indústria de Alimentos S/A.) and cerealcontaining treatment WP, PB or control (no peanuts) in randomised order. The cream of wheat was prepared by adding $56 \mathrm{~g}$ of instant cream of wheat (Original Instant Cream of Wheat, B\&G Foods, Inc.) to brown sugar $(P=8.7 \mathrm{~g} ; \mathrm{PB}=9.6 \mathrm{~g}$; control $=9.9 \mathrm{~g})$ (Lowçucar, LightSweet, Inc.), $1 \mathrm{~g}$ of aspartame sweetener (NutraSweet Company) and $300 \mathrm{ml}$ of water, which was then heated for $1.5 \mathrm{~min}$ in the microwave. For the peanut treatments, $42.5 \mathrm{~g}$ of whole peanuts without skins (Nuts Online Company) (WP treatment) or creamy peanut butter (Arrowhead Mills, The Hain Celestial Group, Inc.) (PB treatment) were added. At minute 240, participants consumed a standard lunch within $10 \mathrm{~min}$ that consisted of white bread ( $50 \mathrm{~g}$ ) (Seven Boys LTDA), strawberry jam ( $89.3 \mathrm{~g}$ ) (Fugini Alimentos LTDA) and water ( $250 \mathrm{ml}$ ) containing $75 \mathrm{~g}$ of available carbohydrate (Table 1). Test breakfasts and lunch meals were matched on palatability, evaluated by appearance, smell, texture and intensity of taste (sweet, salty, bitter and sour) ${ }^{(11)}$.

The breakfast meal's glycaemic index was estimated using the International Glycemic Index Table ${ }^{(23)}$, according to the Wolever \& Jenkins ${ }^{(24)}$ equation (see Supplementary information, available online).

\section{Biochemical measurements}

A measure of $3 \mathrm{ml}$ of blood was collected in a red top vacutainer at each draw. After clotting and centrifugation, insulin, glucose and NEFA concentrations were measured. A measure of $4 \mathrm{ml}$ of blood was collected in an ice-cooled EDTA-plasma vacutainer, and $40 \mu \mathrm{l}$ of dipeptidyl peptidase- 4 inhibiter (Millipore) was added for analysis of GLP-1, and $325 \mu \mathrm{l}$ aprotinin $(500 \mathrm{KIU} / \mathrm{ml})$ (Sigma-Aldrich) was added for PYY and CCK analyses; all samples were handled according to the manufacturer's directions. Insulin and glucose were measured by electrochemiluminescence and the glucose

Table 1. Test breakfast and lunch nutritional composition*

\begin{tabular}{|c|c|c|c|c|}
\hline & \multicolumn{3}{|c|}{ Breakfast } & \multirow[b]{2}{*}{ Lunch } \\
\hline & Control & Peanuts & PB & \\
\hline Energy (kJ) & 1408 & 2514 & 2561 & 1442 \\
\hline Total carbohydrate (g) & 77.9 & $85 \cdot 2$ & 85.6 & 77.6 \\
\hline Available carbohydrate (g) & $75 \cdot 9$ & $81 \cdot 8$ & $80 \cdot 9$ & $75 \cdot 0$ \\
\hline Protein $(\mathrm{g})$ & $6 \cdot 0$ & $17 \cdot 3$ & $16 \cdot 6$ & $5 \cdot 2$ \\
\hline Example of foods provided & $\begin{array}{l}\text { Cream of } \\
\text { wheat }+ \text { OJ }\end{array}$ & $\begin{array}{c}\text { Cream of } \\
\text { wheat }+\mathrm{OJ}+42.5 \mathrm{~g} \mathrm{WP}\end{array}$ & $\begin{array}{r}\text { Cream of wheat }+ \\
\mathrm{OJ}+42.5 \mathrm{~g} \text { PB }\end{array}$ & $\begin{array}{l}\text { White bread }+ \\
\text { strawberry jam }\end{array}$ \\
\hline
\end{tabular}

OJ, orange juice; WP, whole peanuts without skins; PB, peanut butter.

* Based on nutrition label information. 
oxidase method, respectively. Sensitivity of the insulin immunoassay was $1.39 \mathrm{pmol} / 1$ (within-run $\mathrm{CV}$ of $1.9 \%$ ). The glucose oxidase sensitivity was $0.12 \mathrm{mmol} / 1$ (within-run $\mathrm{CV}$ of $0 \cdot 41 \%$ ). NEFA were analysed by an enzymatic colorimetric method on an automated analyser with a sensitivity of $0 \cdot 14 \mu \mathrm{mol} / \mathrm{l}$ (within-run CV of $0.75 \%$ ). GLP-1, PYY and CCK were assessed by ELISA. Sensitivity of the GLP-1 assay was $2 \mathrm{pmol} / \mathrm{L}$ (within-run $\mathrm{CV}$ of $7 \cdot 4 \%$ ) (Linco Research), PYY sensitivity was $1.4 \mathrm{pg} / \mathrm{ml}$ (within-run CV of $0.86 \%$ ) (Millipore) and CCK sensitivity was $3.86 \mathrm{ng} / \mathrm{ml}$ (within-run $\mathrm{CV}<10 \%$ ) (Ray Biotech, Inc.).

\section{Appetite profile}

Appetite ratings - hunger, satiety, desire to eat and desire to consume specific food types (salty, sweet or greasy) - were scored at baseline and immediately after blood sample collection on a $100 \mathrm{~mm}$ visual analogue scale anchored with descriptors of 'not at all' and 'extremely' ${ }^{\text {(11) }}$. The visual analogue scales were completed eight times throughout the test day at $-10,15$, $45,60,90,120,180$ and $240 \mathrm{~min}$ after consumption of the test breakfast (first-meal responses) and seven times at 265, 295, 310, 340, 370, 430 and $490 \mathrm{~min}$ (second-meal responses). After leaving the laboratory, participants recorded all food consumed and filled out the appetite ratings at 550, 610, 670 and $730 \mathrm{~min}$. Therefore, appetite ratings were assessed for a total of $12 \mathrm{~h}$.

\section{Food intake assessment}

Before the beginning of the study, all participants were instructed to register their food intake on three non-consecutive days (two week days and one weekend day) ${ }^{(25)}$ to describe their eating habits at baseline. In addition, after leaving the laboratory (490 min), participants were asked to keep a food record for the rest of the day. To ensure accuracy, participants received written guidelines and were trained to estimate the consumed food portions using household items. Participants received a standardised record form to register the type and amount of foods and beverages consumed before the beginning of the study (baseline) and after they left the laboratory on each test meal day. Each dietary record was reviewed in the presence of the volunteer in order to ensure its accuracy and completeness. Food portions were converted into grams and the subsequent meal energy intake, $24 \mathrm{~h}$ total post-meal energy intake, macronutrients and fibre consumption were analysed using the software DietPro 5.0i (A.S. System).

\section{Statistical analyses and calculations}

While the incremental AUC (IAUC) (glucose, insulin, GLP-1, PYY, CCK and appetite sensations) was calculated excluding the values below the baseline values, the incremental area above the curve (IAAC; NEFA) was obtained excluding any value above (IAAC) the baseline values ${ }^{(26)}$. IAUC and IAAC were computed using the trapezoidal method, using Slide Write software, version 7.0 (Advanced Graphics Software, Inc.). Data analyses were conducted considering the following periods of time: $0-490 \mathrm{~min}$ (defined as the whole study response), 0-240 min (defined as the first-meal response),
240-490 min (defined as the second-meal response) and 490-730 min (defined as the post-laboratory period).

Residual plots of data were examined to consider homogeneity of variance and the Shapiro-Wilk test was performed to determine data distribution normality, and a logarithmic transformation was used when required. Repeated-measures ANOVA was used to examine the effects of meal and time on the postprandial responses and appetite sensations. This was performed using PROC MIXED (SAS, version 9.1). Post hoc comparisons were made using Bonferroni adjustments for meal and for meal $\times$ time interactions when significant. ANOVA was used to examine the effect of meal on IAUC, IAAC and food intake, and, when appropriate, post hoc comparisons were made using the Tukey's test. PROC TTEST (SAS, version 9.1) was applied to compare morning $v$. afternoon IAUC/IAAC and peak values of each treatment on each variable. All statistical analyses were performed using the Statistical Analysis System software package, version 9.1 (SAS Institute, Inc.). The criterion for statistical significance was $P<0.05$ (two-tailed). The results related to the characterisation of the sample and dietary intake are presented as mean values and standard deviations, and biochemistry and appetite responses are presented as mean values with their standard errors.

\section{Results}

\section{Participant characteristics}

Two participants did not return their visual analogue scale and diet records and data analyses were conducted on thirteen participants. Their baseline characteristics are shown in Table 2. There were no differences in body weight $(P=0.95)$, capillary glucose $(P=0.93)$ and number of hours of sleep $(P=0.39)$ before the beginning of each experimental session. None of the feed-deprived variables assessed in the study differed ( $P>0 \cdot 78)$

\section{Blood glucose}

Although the first-meal glycaemic response IAUC did not differ between the breakfast treatments $(P=0.48)$, the

Table 2. Baseline characteristics of the participants (Mean values and standard deviations)

\begin{tabular}{lrr}
\hline Variables & Mean & SD \\
\hline Age (years) & $8 \cdot 61$ & 35.33 \\
Waist circumference $(\mathrm{cm})$ & 100.77 & 6.34 \\
BMI $\left(\mathrm{kg} / \mathrm{m}^{2}\right)$ & 32.36 & 1.25 \\
Body fat $(\%)$ & 36.74 & 3.56 \\
Systolic blood pressure $(\mathrm{mmHg})$ & 118.00 & 7.75 \\
Diastolic blood pressure $(\mathrm{mmHg})$ & 76.00 & 7.37 \\
Feed-deprived blood glucose $(\mathrm{mmol} / \mathrm{l})$ & 4.99 & 0.49 \\
Blood glucose OGTT (mmol/l) & 6.06 & 1.39 \\
HOMA-IR* & 2.79 & 1.43 \\
HOMA1- $\beta \% \dagger$ & 50.22 & 22.56
\end{tabular}

OGTT, oral glucose tolerance test; HOMA-IR, homeostasis model assessment insulin resistance index; HOMA1- $\beta$, homeostasis model assessment pancreatic $\beta$-cell function

${ }^{*}$ HOMA-IR $=($ fasting insulin $(\mu \mathrm{U} / \mathrm{ml}) \times$ fasting glucose $(\mathrm{mmol} / \mathrm{l})) / 22.5$. (Insulin: $1 \mu \mathrm{U} / \mathrm{ml}=6.945 \mathrm{pmol} / \mathrm{l}$.)

†HOMA $1-\beta=(20 \times$ fasting insulin $(\mu \mathrm{U} / \mathrm{ml})) /($ fasting glucose $(\mathrm{mmol} / \mathrm{l})-3.5)$. (Insulin: $1 \mu \mathrm{U} / \mathrm{ml}=6.945 \mathrm{pmol} / \mathrm{l}$.) 
ingestion of the $\mathrm{PB}$ meal resulted in significantly lower second-meal glycaemic response IAUC $(P=0.03)$, as compared with the control breakfast. The $\mathrm{PB}$ and the WP meals' glucose IAUC responses $(0-490 \mathrm{~min})$ were 18.7 and $14.4 \%$ lower than the control meal $(P=0 \cdot 48)$, respectively (Table 3). The inclusion of peanuts reduced the glycaemic index of the breakfast meals from $60 \cdot 8$ (control) to $56 \cdot 2$ (PB) and 58.4 units (WP) (Table 1).

There was a time $\times$ meal interaction on the first-meal postprandial glycaemic response $(P=0 \cdot 03)$. Post hoc comparisons indicated a lower glucose concentration at 15 and $310 \mathrm{~min}$ (both $P=0.04$ ), and a tendency for lower glucose concentration at $45 \mathrm{~min}(P=0.05)$ after the $\mathrm{PB}$ compared with the control breakfast (Fig. 2(a)). Mean first- (15 min) and second-(295 min) meal glucose peaks did not differ $(P>0.26)$ according to the study treatment. The first-meal glycaemic IAUC responses for all treatments were significantly lower $(P<0.03)$ than the second-meal responses.

\section{Serum insulin}

The WP and the PB meals' insulin IAUC responses (0-490 min) were $50 \cdot 2$ and $23 \cdot 1 \%$ higher than the response to the control meal $(P=0.53)$, respectively (Table 3$)$. Post hoc comparisons indicated a higher insulin concentration for the WP meal at $45 \mathrm{~min}(P=0.03)$ and for the PB meal at $120(P=0.04)$ and $370 \mathrm{~min}(P=0.02)$ compared with the control breakfast (Fig. 2(b)). The first-meal insulinaemic response peaks (WP: $45 \mathrm{~min}$; PB: $15 \mathrm{~min}$; and control: $15 \mathrm{~min})$ were higher $(P<0.04)$ compared with the second meal (WP: 310 min; PB: $370 \mathrm{~min}$; and control: $295 \mathrm{~min}$ ) for all the treatments. The WP and the PB first-meal insulinaemic responses $(P<0.002)$ were higher compared with the second-meal responses.

\section{NEFA}

The PB first-meal (0-240 min) NEFA IAUC was lower $(P=0.02)$ compared with the control breakfast. The WP and the PB NEFA IAUC responses (0-490 min) were 44.0 and $21.4 \%$ lower than that obtained for the control meal $(P=0.06)$, respectively (Table 3$)$. There was a time $\times$ meal interaction on the first-meal postprandial NEFA response $(P=0 \cdot 002)$. Post hoc comparisons indicated a lower NEFA concentration at $90(P=0.02)$ and $120 \mathrm{~min}(P=0.02)$, and a tendency for lower NEFA concentration at $180 \mathrm{~min}(P=0.06)$ after the PB compared with the control breakfast (Fig. 2(c)). Peak NEFA did not differ between the first and the second meals according to the study treatment $(P>0 \cdot 44)$. There was no difference between the meal time period for NEFA IAUC responses among the study treatments.

\section{Glucagon-like peptide-1}

The WP and the PB GLP-1 IAUC responses (0-490 min) were markedly but not significantly higher (116.5 and $131.0 \%$, respectively) than the observed rise for the control meal ( $P=0 \cdot 46$ ) (Table 3 ). GLP-1 concentrations did not vary significantly between the treatments (Fig. 3(a)). The PB first- 


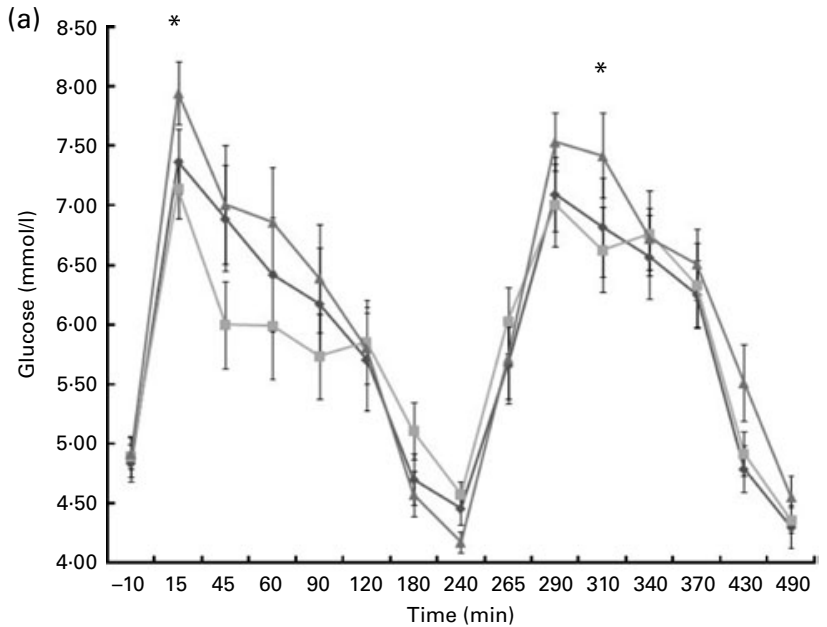

(b)

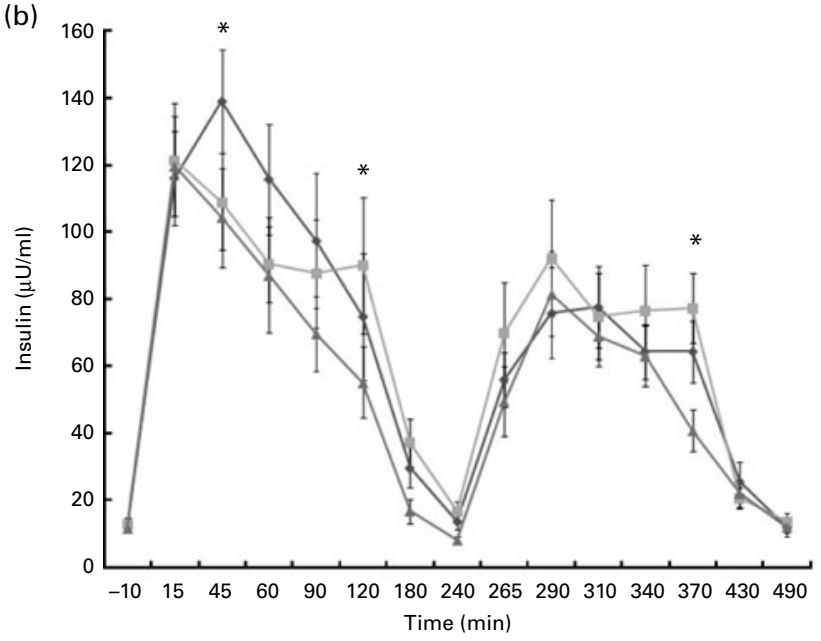

(c)

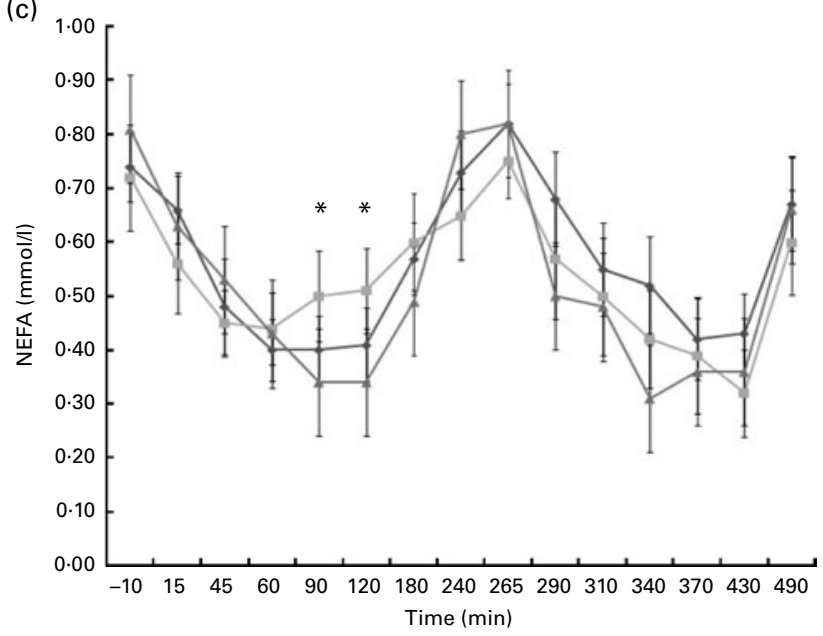

Fig. 2. Fasting and postprandial (a) glucose, (b) insulin and (c) NEFA responses to the breakfast meals containing peanuts $(\rightarrow)$, peanut butter $(-)$ or control (- no peanuts). Values are means, with their standard errors represented by vertical bars. ${ }^{\star}$ Mean values were significantly different $(P<0.05)$. Insulin: $1 \mu \mathrm{U} / \mathrm{ml}=6.945 \mathrm{pmol} / \mathrm{l}$.

meal GLP-1 response $(P=0 \cdot 008)$ was higher compared with the second-meal response. Peak GLP-1 did not differ between the first and the second meals according to study treatment $(P>0 \cdot 32)$.

\section{Peptide $Y Y$}

The PB and the WP first-meal (0-240 min) PYY IAUC were higher $(P=0.006)$ compared with the control breakfast (Table 3 ). There was also a time $\times$ meal interaction on the first-meal postprandial PYY response $(P=0 \cdot 004)$. Post boc comparisons indicated a higher PYY concentration at 120 $(P=0.04), 180(P=0.01)$ and $240 \mathrm{~min}(P=0.01)$ after the WP compared with the control breakfast (Fig. 3(b)).

\section{Cholecystokinin}

The WP first-meal CCK IAUC responses (0-240 min) were three-fold higher, albeit not significantly, than the control meal ( $P=0.65$ ) (Table 3 ). CCK concentrations did not vary significantly between the treatments (Fig. 3(c)).

\section{Appetite sensations}

During the post-laboratory period (490-730 min), the WP and the PB IAUC desire to eat were lower $(P=0.04)$ compared with the control breakfast. However, self-reported fullness was significantly higher at $610 \mathrm{~min}$ after the control compared with the WP $(P=0 \cdot 001)$ and the PB $(P=0 \cdot 01)$ breakfast consumption. There was a lower desire to eat something fatty at 610 and $670 \mathrm{~min}$ after the control compared with the WP $(P=0.02)$ and the PB $(P=0.03)$ breakfast meals. There was a significant time $\times$ meal interaction for desire to eat something sweet $(P=0.03)$ after the participants left the laboratory (490-730 min). Post boc comparisons revealed a higher $(P=0.02)$ desire to eat something sweet at $610 \mathrm{~min}$ for the PB compared with the WP breakfast meals. There was no treatment effect on first- and second-meal appetitive responses.

\section{Food intake}

Habitual intake and the WP breakfast fat consumption was higher $(P=0.003)$ than observed after the control breakfast. On the other hand, the control breakfast carbohydrate consumption was higher $(P=0.01)$ than the habitual intake (Table 4). There was no treatment effect on daily energy $(P=0.56)$, protein $(P=0.11)$ or fibre $(P=0 \cdot 18)$ intake compared with the habitual intake. Daily food intake did not differ $(P>0.34)$ according to the study treatment after the participants left the laboratory.

\section{Discussion}

The primary aim of the present work was to compare the effects of peanut consumption (WP or PB) on first- and second-meal responses. A secondary aim was to contrast responses to nut form, i.e. whole nut $v$. butter, on indices related to obesity and T2DM risk. All test meals (control, PB and WP) were equally palatable and had a medium glycaemic index (59.9-66.3).

Compared with the control meal, consumption of a breakfast meal containing $42.5 \mathrm{~g}$ of $\mathrm{PB}$ reduced the firstmeal (0-240 min) NEFA concentrations and early glycaemic 


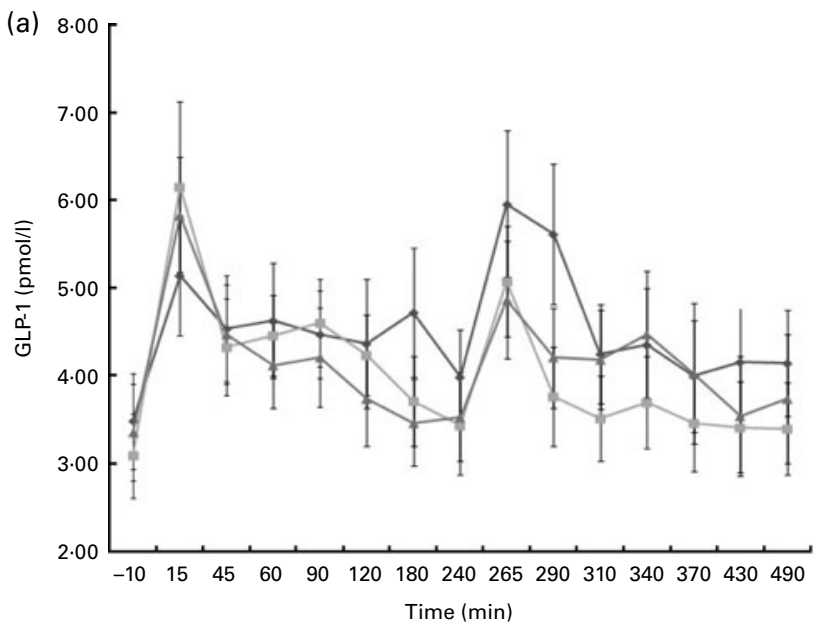

(b)

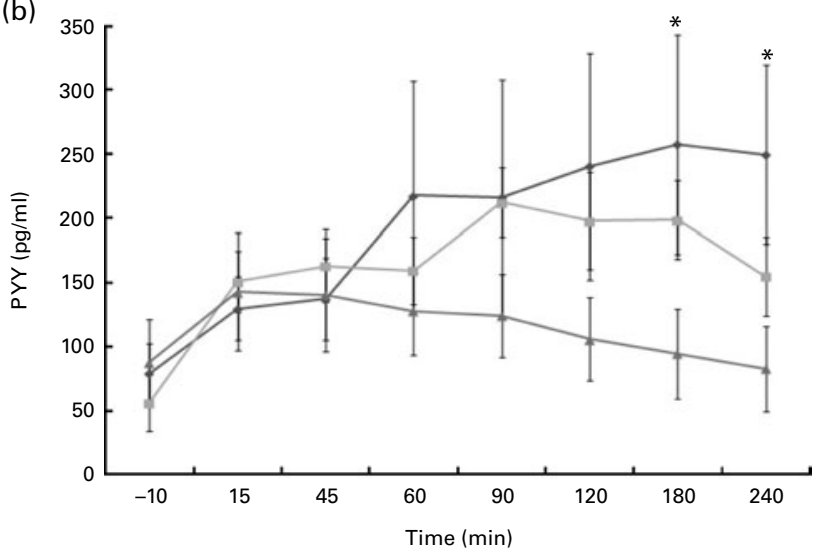

(c)

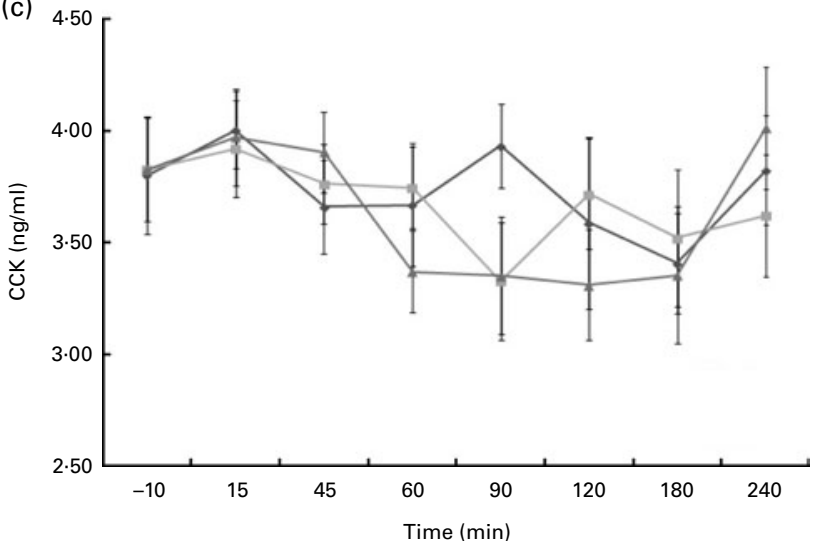

Fig. 3. Fasting and postprandial (a) glucagon-like peptide-1 (GLP-1), (b) peptide $Y Y$ (PYY) and (c) cholecystokinin (CCK) responses to the breakfast meals containing peanuts $(\rightarrow)$, peanut butter $(\rightarrow)$ or control $(\rightarrow$, no peanuts). Values are means, with their standard errors represented by vertical bars. * Mean values were significantly different $(P<0 \cdot 05)$.

response. In addition, the consumption of WP and PB elicited a significant increase in the postprandial PYY concentration (180 and $240 \mathrm{~min}$ ) as well as marked, but non-significant, GLP-1 and CCK elevations ( $0-240 \mathrm{~min})$. A reduction on the second-meal (240-490 min) glycaemic response was also observed after PB consumption. It also reduced the desire to eat from 480 to $730 \mathrm{~min}$ after breakfast. Only preliminary evidence is available on potential mechanisms accounting for these outcomes. The observed effects may favour obesity and T2DM prevention and control, as discussed later.

\section{Glucose metabolism}

Although reduced glycaemic responses after peanut ${ }^{(27,28)}$ and almond $^{(29,30)}$ consumption have been reported by other investigators, only one trial with almonds has examined the effect of nut consumption on the second-meal glycaemic response. It noted improved blood glucose control over successive meals when almonds or almond oil were added to high-glycaemic-index breakfast and lunch meals. In this trial, almond butter was not effective at moderating blood glucose excursions after the meals ${ }^{(31)}$. No explanation for this finding was apparent, as the likely mediator, unsaturated fat provided by the almonds, would have been more bioaccessible from the almond butter than whole almonds. The present trial examined the same effect with peanuts, allowing determination of the reliability and specificity of the responses. The results of the present study indicate that, in women at elevated risk for T2DM, the consumption of PB leads to a reduced glycaemic response acutely after breakfast and also $240-480 \mathrm{~min}$ later. In contrast to the findings with almonds, the whole nut responses were slightly weaker. Whether the difference between peanuts and almonds stems from greater bioaccessibility of lipids and lipophylic compounds from peanuts warrants further study. Greater fat availability may reduce the gastric emptying rate, decrease carbohydrate absorption rate and favour a reduction of glycaemic response ${ }^{(8)}$. Thus, differences in the physical form of consumed peanuts can affect the postprandial glycaemic response. If this hypothesised mechanism holds, the finding with almond butter remains to be clarified.

It has been documented that the addition of fat and protein to meals leads to a reduction of glycaemic response. These effects have been attributed to delayed gastric emptying rate $^{(32)}$ and to increased insulin secretion mediated by intestinal hormones (glucose-dependent insulinotropic polypeptide and GLP-1) ${ }^{(33)}$. Although, in the present study, the fat and protein content of peanut and the PB breakfasts were very similar pre-ingestively, the incrementally greater reduction on the second-meal (240-490 min) glycaemic response observed after PB consumption suggests that the effect that these macronutrients exert on glycaemic response may also depend on food form.

According to the second-meal phenomenon, a reduction of the first-meal NEFA decreases the second-meal postprandial glycaemic response ${ }^{(34)}$. This effect is probably due to improvement in insulin sensitivity, as an increase in fatty acid concentration impairs insulin signalling downstream to the insulin receptor, leading to insulin resistance ${ }^{(35)}$. Therefore, the lower NEFA concentrations obtained after the consumption of the PB breakfast may be responsible for the lower glycaemic and insulinemic responses 240-480 min later. The extent of rise in postprandial glycaemia is considered a risk factor for $\mathrm{CVD}^{(36)}$. The results of the present study suggest that $\mathrm{PB}$ 
Table 4. Daily habitual intake and on each study session

(Mean values and standard deviations)

\begin{tabular}{|c|c|c|c|c|c|c|c|c|}
\hline & \multicolumn{2}{|c|}{$\mathrm{HI}$} & \multicolumn{2}{|c|}{ WP } & \multicolumn{2}{|c|}{ PB } & \multicolumn{2}{|c|}{$\begin{array}{l}\text { Control break- } \\
\text { fast }\end{array}$} \\
\hline & Mean & SD & Mean & SD & Mean & SD & Mean & SD \\
\hline Energy (kJ) & 7906 & 1573 & 8772 & 2334 & 8136 & 1620 & 7842 & 1696 \\
\hline Carbohydrate (g) & $245 \cdot 4^{\mathrm{a}}$ & $63 \cdot 8$ & $286 \cdot 8^{a, b}$ & $40 \cdot 8$ & $293 \cdot 0^{a, b}$ & $42 \cdot 4$ & $311.8^{b}$ & $58 \cdot 0$ \\
\hline Fat $(g)$ & $68 \cdot 2^{\mathrm{a}}$ & $18 \cdot 3$ & $67 \cdot 1^{\mathrm{a}}$ & 33.5 & $61 \cdot 2^{a, b}$ & 23.7 & $37.7^{b}$ & $14 \cdot 0$ \\
\hline Protein (g) & $70 \cdot 2$ & $20 \cdot 4$ & $79 \cdot 6$ & $35 \cdot 4$ & $64 \cdot 2$ & $19 \cdot 8$ & 54.0 & $14 \cdot 0$ \\
\hline Dietary fibre (g) & $19 \cdot 9$ & 9.9 & $14 \cdot 8$ & 4.0 & $15 \cdot 0$ & $5 \cdot 1$ & $13 \cdot 1$ & 5.6 \\
\hline
\end{tabular}

$\mathrm{HI}$, habitual intake; WP, whole peanuts without skins; PB, peanut butter.

${ }^{a, b}$ Mean values within a row with unlike superscript letters were significantly different $(P<0.05)$.

consumption might exert a protective effect against this disorder.

Peanuts contain high concentrations of arginine and protein, which are insulin secretagogues ${ }^{(5)}$. They also have a high $\mathrm{Zn}$ content that could stimulate the tyrosine kinase receptor, improving insulin sensitivity ${ }^{(37)}$. The high content of MUFA in PB might also increase insulin sensitivity and favour a reduction in the glycaemic response in insulin-resistant participants through increased GLP-1 secretion ${ }^{(38)}$. This also may explain the second-meal glycaemic IAUC reduction observed in the present study.

\section{Appetite control and food intake}

In the present trial, there was a higher mean GLP-1 IAUC in the PB and the WP sessions compared with the control session. This is consistent with the elevated insulin concentrations for these treatments. Similar results were noted in another study where there was a significant increase in the GLP-1 concentration $240 \mathrm{~min}$ after the consumption of Korean pine nut oil (Pinus koraiensis) compared with the control $^{(39)}$. A trend in this direction has also been reported for almonds (whole and butter) ${ }^{(31)}$.

The high energy density, fibre and protein content of peanuts may augment their satiety property and promote body weight management ${ }^{(40)}$. A reduction in hunger and in food intake has been reported in response to nut consumption (peanuts, PB, almonds and chestnuts) compared with foods with low energy density (e.g. rice cake and pickles) and a no-preload condition in healthy participants ${ }^{(41)}$. In a recent study, higher fullness ratings were observed after almond meal (whole and butter) than control breakfast meals in glucose-intolerant participants ${ }^{(31)}$. In the present study, there was a lower desire to eat in response to peanut meals (whole and butter) compared with the lower-energy density meal (control meal).

\section{Conclusion}

These results indicate that $\mathrm{PB}$ can be added to breakfast meals to favour a reduction on the second-meal glycaemic and the first-meal NEFA responses, an increase on the first-meal PYY concentrations and a reduction on the desire to eat in obese women with high T2DM risk. Effects of WP were in a similar direction to the PB meal, but not as great. The present findings have practical implications, because peanuts and $\mathrm{PB}$ are often served in breakfast meals worldwide. Long-term feeding trials are now required to assess the feasibility and benefits associated with chronic peanut or tree nut consumption.

\section{Supplementary material}

To view supplementary material for this article, please visit http://dx.doi.org/10.1017/S0007114512004217

\section{Acknowledgements}

We are grateful to Leandro Licursi de Oliveira, Federal University of Viçosa, Brazil, for the assistance on GLP-1, CCK and PYY concentration determinations and to Alexandre Azevedo Novello, Federal University of Viçosa, Brazil, for the assistance on glucose, insulin and NEFA concentration determinations. We also thank the undergraduate project students (Millena Coutinho Tonázio and Ana Cecília Santos de Totaro) who provided technical assistance with the sample collection and data entry. The present project was supported by grants from the Brazilian government organisations (CAPES and FAPEMIG; 472297/2009-0), and the United States Agency for International Development through the Peanut Collaborative Research Support Program. N. M. B. C., J. B., R. C. G. A. and R. D. M. designed the research; C. E. G. R. and D. N. R. conducted the research; C. E. G. R., and R. C. G. A. analysed the data; C. E. G. R., D. N. R., N. M. B. C., J. B., R. C. G. A. and R. D. M. wrote the paper; and C. E. G. R. and R. C. G. A. had primary responsibility for the final content. All authors read and approved the final manuscript. The authors declare no conflict of interest.

\section{References}

1. Mokdad AH, Ford ES, Bowman BA, et al. (2003) Prevalence of obesity, diabetes, and obesity-related health risk factors, 2001. JAMA 289, 76-79.

2. American Diabetes Association (2008) Nutrition Recommendations and Interventions for Diabetes. Diabetes Care 31, S61-S78.

3. Kendall CWC, Esfahani A, Truan J, et al. (2010) Health benefits of nuts in prevention and management of diabetes. Asia Pac J Clin Nutr 19, 110-116. 
4. Sabaté J \& Ang Y (2009) Nuts and health outcomes: new epidemiologic evidence. Am J Clin Nutr 89, 1643S-1648S.

5. O'Neil CE, Keast DR, Fulgoni VL, et al. (2010) Tree nut consumption improves nutrient intake and diet quality in US adults: an analysis of National Health and Nutrition Examination Survey (NHANES) 1999-2004. Asia Pac J Clin Nutr 19, 142-150.

6. Allen LH (2008) Priority areas for research on the intake, composition, and health effects of tree nuts and peanuts. J Nutr 138, 1763S-1765S.

7. Ellis PR, Kendall CW, Ren Y, et al. (2004) Role of cell walls in the bioaccessibility of lipids in almond seeds. Am J Clin Nutr 80, 604-613.

8. Gentilcore D, Chaikomin R, Jones KL, et al. (2006) Effects of fat on gastric emptying of and the glycemic, insulin, and incretin responses to a carbohydrate meal in type 2 diabetes. J Clin Endocrinol Metab 91, 2062-2067.

9. Cassady BA, Hollis JH, Fulford AD, et al. (2009) Mastication of almonds: effects of lipid bioaccessibility, appetite, and hormone response. Am J Clin Nutr 89, 794-800.

10. Wolever TMS \& Mehling C (2003) Long-term effect of varying the source or amount of dietary carbohydrate on postprandial glucose, insulin, triacylglycerol, and free fatty acid concentrations in participants with impaired glucose tolerance. Am J Clin Nutr 77, 612-621.

11. Flint A, Raben A, Blundell JE, et al. (2000) Reproducibility, power and validity of visual analogue scales in assessment of appetite sensations in single test meal studies. Int J Obes Relat Metab Disord 24, 38-48.

12. World Health Organization (2000) Defining the problem of overweight and obesity. In Obesity: Preventing and Managing the Global Epidemic: Report of a WHO Consultation. Technical Report Series no. 894, pp. 241-243. Geneva: WHO.

13. Heyward VH, Stolarczyk LM. (2000). Avaliação da composição corporal aplicada (Applied Body Composition Assessment), 243p. São Paulo: Manole.

14. Expert Panel on Detection, Evaluation, and Treatment of High Blood Cholesterol in Adults (2001) Executive Summary of The Third Report of The National Cholesterol Education Program (NCEP) Expert Panel on Detection, Evaluation, And Treatment of High Blood Cholesterol In Adults (Adult Treatment Panel III). JAMA 285, 2486-2497.

15. Lukaski HC, Bolonchuk WW, Hall CB, et al. (1986) Validation of tetrapolar bioelectrical impedance method to assess human body composition. J Appl Physiol 60, 1327-1332.

16. Pickering TG, Hall JE, Appel LJ, et al. (2005) Recommendations for blood pressure measurement in humans and experimental animals. Hypertension 45, 142-161.

17. Johansson G \& Westerterp KR (2008) Assessment of the physical activity level with two questions: validation with doubly labeled water. Int J Obes 32, 1031-1033.

18. Mifflin M, St Jeor S, Hill L, et al. (1990) A new predictive equation for resting energy expenditure in healthy individuals. Am J Clin Nutr 51, 241-247.

19. American Diabetes Association (2009) Diagnosis and classification of diabetes mellitus. Diabetes Care $\mathbf{3 2}$, Suppl. 1, S62-S67.

20. Matthews DR, Hosker JP, Rudenski AS, et al. (1985) Homeostasis model assessment: insulin resistance and beta-cell function from fasting plasma glucose and insulin concentrations in man. Diabetologia 28, 412-419.

21. Geloneze B, Repetto EM, Geloneze SR, et al. (2006) The threshold value for insulin resistance (HOMA-IR) in admixtured population IR in the Brazilian Metabolic Syndrome Study. Diabetes Res Clin Pract 72, 219-220.

22. Food and Drug Administration, Office of Nutritional Products, Labeling and Dietary Supplements (2003) Qualified
Health Claims about Cardiovascular Disease Risk: Letter of Enforcement Discretion-nuts and Heart Disease (Docket no. 02P-0505)

23. Atkinson FS, Foster-Powell K \& Brand-Miller JC (2008) International tables of glycemic index and glycemic load values: 2008. Diabetes Care 31, 2281-2283.

24. Wolever T \& Jenkins D (1986) The use of the glycemic index in predicting the blood glucose response to mixed meals. Am J Clin Nutr 43, 167-172.

25. Serra-Majem L \& Aracenta-Bartrina J (1995) Introdución a la epidemiologia nutricional (Introduction to nutritional epidemiology). In Nutrición y Salud Pública (Nutrition and Public Health), pp. 59-65. Barcelona: Masson.

26. Wolever TMS (2004) Effect of blood sampling schedule and method of calculating the area under the curve on validity and precision of glycaemic index values. Br J Nutr $\mathbf{9 1}$, 295-300.

27. Reis CEG, Bordalo LA, da Rocha ALC, et al. (2011) Ground roasted peanuts leads to a lower post-prandial glycemic response than raw peanuts. Nutr Hosp 26, 745-750.

28. Johnston CS \& Buller AJ (2005) Vinegar and peanut products as complementary foods to reduce postprandial glycemia. J Am Diet Assoc 105, 1939-1942.

29. Jenkins DJA, Kendall CWC, Josse AR, et al. (2006) Almonds decrease postprandial glycemia, insulinemia, and oxidative damage in healthy individuals. J Nutr 136, 2987-2992.

30. Josse AR, Kendall CWC, Augustin LSA, et al. (2007) Almonds and postprandial glycemia - a dose-response study. Met Clin Exp 56, 400-404.

31. Mori AM, Considine RV \& Mattes RD (2011) Acute and secondmeal effects of almond form in impaired glucose tolerant adults: a randomized crossover trial. Nutr Metab 8, 1-6.

32. Feinle C, O'Donovan D, Doran S, et al. (2003) Effects of fat digestion on appetite, APD motility, and gut hormones in response to duodenal fat infusion in humans. Am J Physiol Gastrointest Liver Physiol 284, 798-807.

33. Collier GR, Greenberg GR, Wolever TMS, et al. (1988) The acute effect of fat on insulin secretion. J Clin Endocrinol Metab 66, 323-326.

34. Jovanovic A, Gerrard J \& Taylor R (2009) The second-meal phenomenon in type 2 diabetes. Diabetes Care 32, 1199-1201.

35. Saini V (2010) Molecular mechanisms of insulin resistance in type 2 diabetes mellitus. World J Diabetes 1, 68-75.

36. Cavalot F, Petrelli A, Traversa M, et al. (2006) Postprandial blood glucose is a stronger predictor of cardiovascular events than fasting blood glucose in type 2 diabetes mellitus, particularly in women: lessons from the San Luigi Gonzaga Diabetes Study. J Clin Endocrinol Metab 91, 813-819.

37. Jansen J, Karges W \& Rink L (2009) Zinc and diabetes - clinical links and molecular mechanisms. J Nutr Biochem 20 , 399-417.

38. Paniagua JA, de la Sacristana AG, Sanchez E, et al. (2007) A MUFA-rich diet improves posprandial glucose, lipid and GLP-1 responses in insulin-resistant participants. J Am Coll Nutr 26, 434-444.

39. Pasman W, Heimerikx J, Rubingh C, et al. (2008) The effect of Korean pine nut oil on in vitro CCK release, on appetite sensations and on gut hormones in post-menopausal overweight women. Lipids Health Dis 7, 1-10.

40. Mattes RD \& Dreher ML (2010) Nuts and healthy body weight maintenance mechanisms. Asia Pac J Clin Nutr 19 137-141.

41. Kirkmeyer SV \& Mattes RD (2000) Effects of food attributes on hunger and food intake. Int J Obes Relat Metab Disord 24, 1167-1175. 